\title{
A rare case: Hypothenar Hammer syndrome
}

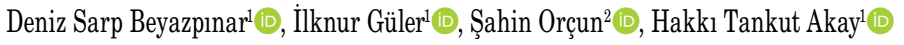 \\ ${ }^{1}$ Department of Cardiovascular Surgery, Medicine Faculty of Başkent University, Ankara, Turkey \\ ${ }^{2}$ Department of Orthopedics and Traumatology, Medicine Faculty of Başkent University, Ankara, Turkey
}

\begin{abstract}
Hypothenar Hammer syndrome (HHS) was firstly described by Von Rosen. It is a rare occupational disease and is caused by major or repeated trauma and often affect ulnar artery on hypothenar region. This region is only covered by skin and subcutaneous tissue, and has a comparatively less protected anatomical structure. A 55-year-old male patient presented with complaints of cold and knob on his left hand. After conforming the diagnosis with arteriography, aneurysmal segment was resected and saphenous vein was interposed on the resected segment. The patient was followed for one year without any complication. In conclusion, with accurate diagnosis and appropriate treatment, symptoms can be eliminated and life quality can be improved.
\end{abstract}

Keywords: Artery aneurysm; Hypothenar Hammer syndrome; trauma; ulnar artery aneurysm.

Hypothenar Hammer syndrome (HHS), which was first defined by Von Rosen, is a medical condition caused by the occlusion of arteries of the hand, particularly the ulnar artery. ${ }^{[1,2]}$

Ulnar artery goes through the Guyon's canal in the hypothenar region. This region is only covered by skin and subcutaneous tissue, and has a comparatively less protected anatomical structure. ${ }^{[3]}$

A single major or repeated trauma, and working with vibrational equipment can lead to arterial intimal damage which results in platelet aggregation and thrombus formation. Eventually, embolization occurs and it leads to tissue hypoxia. ${ }^{[4]}$

In this article, we present a patient with HHS.

\section{CASE REPORT}

A 55-year-old male was admitted to our outpatient clinic with complaints of cold and knob in the left hand. He reported a few year progressive pain and cold intolerance in his left hand. He was working as a journalist for a long time. His family and medical history was non-remarkable. Physical examination and medical tests including and medical blood pressure, pulses, Allen's test, echocardiogram, electrocardiogram, and radiography revealed nonspecific findings. On angiography, there was an aneurysm on the ulnar artery at the hypothenar area.

In our case, the Allen test was negative. However, color Doppler ultrasonography showed an aneurysm, although it was not enough to decide surgery method and graft for anastomosis was needed. Therefore, we performed arteriography to decide surgery method.

As the ulnar nerve is close to ulnar artery tract, we separated and hung the ulnar nerve to protect. In addition, we protected the Guyon's canal. Finally, we excised the aneurysm and interposed the saphenous vein graft between the intact ends. We used 7/0 prolene sutures for anastomosis, after completing the anastomosis bleeding control. Drains were placed. Subcutaneous tissue was closed with 2/0 Vicryl.

Received: April 06, 2018 Accepted: May 28, 2018 Published online: June 11, 2018

Correspondence: Deniz Sarp Beyazpınar, MD. Başkent Üniversitesi Tıp Fakültesi, Kalp ve Damar Cerrahisi Anabilim Dalı, 06790 Etimesgut, Ankara, Turkey. e-mail: dsarpbeyazpinar@gmail.com 


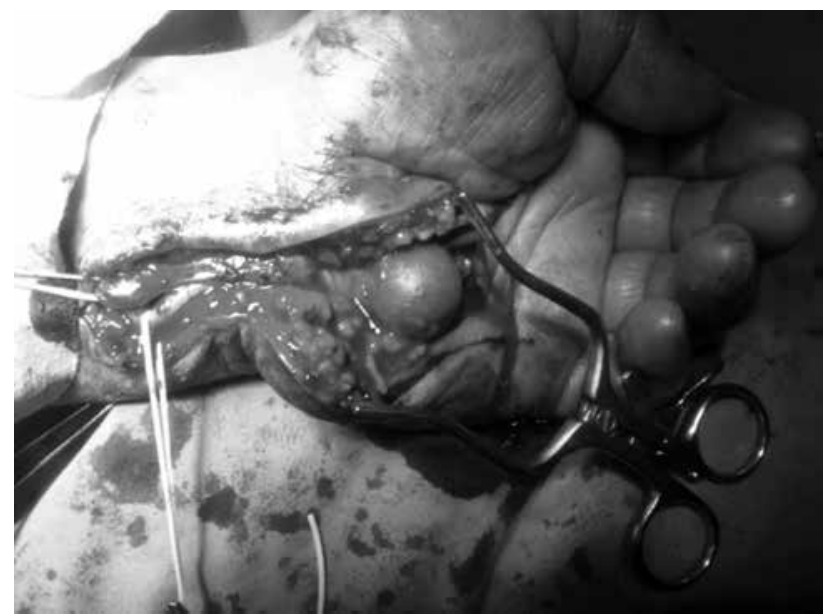

Figure 1. Ulnar artery aneurysm in palmar area.

Cutaneous tissue was closed with 4/0 Vicryl. On the operation day, there was no drainage and we took out drains in the postoperative first day. In the postoperative third day, the patient was discharged. In our patient, we used dual antiaggregant therapy which consists of acetyl salicylic acid and clopidogrel. The patient was followed for one year without any complication. In the first year control, both radial and ulnar pulses were palpable and Doppler USG showed the patency of the graft.

\section{DISCUSSION}

Hand trauma is important for most of the patients with HHS. In addition, smoking and the presence of connective tissue disease are the predisposing factors for this syndrome.

In the diagnosis, other causes of digital ischemia such as atherosclerosis, thromboangiitis obliterans (Buerger disease), and arterial embolism and diabetic or collagen vascular disease must be eliminated. There was no other effected extremities and no typical angiographic findings to support the diagnosis of thromboangiitis obliterans (Buerger's disease). In our case, pain and cold intolerance suggested Raynaud's phenomenon; however, there was no symmetrical involvement on the other hand. Slow-onset also ruled out the diagnosis of arterial embolism. Main symptoms are same almost all of these disease; cold intolerance, cold in finger, dysesthesia, pain, ulcers and a pulsatile mass. Medical history, physical examination, Doppler ultrasonography, and the gold standard angiography helped us in the differential diagnosis.

In HHS, the main treatment methods are conservative, medical or surgical. In medical methods, thrombolysis (recombinant tissue-type plasminogen activator, urokinase and streptokinase), heparin, anticoagulants, vasodilators (calcium canal blockers, nitroglycerine) can be useful. Also, conservative treatment (hand care, protecting hand from trauma) can be useful.

In conclusion, HHS is not rare as thought to be. It is one of the causes of the upper limp digital ischemia and it is a curable and preventable disease. Before the irreversible consequences take place, diagnosis must be cleared and the treatment must be started.

\section{Declaration of conflicting interests}

The authors declared no conflicts of interest with respect to the authorship and/or publication of this article.

\section{Funding}

The authors received no financial support for the research and/or authorship of this article.

\section{REFERENCES}

1. von Rosen S. Ein Fall Von Synovialem Sarkoendotheliom Des Kniegelenks, Acta Orthopaedica Scandinavica 1937;8:191-207.

2. Şahin MŞ, Özyürekoğlu T, Çakmak G. Hypothenar hammer syndrome: a case series and literature review. Eklem Hastalik Cerrahisi 2015;26:11-5.

3. Wheatley MJ, Marx MV. The use of intra-arterial urokinase in the management of hand ischemia secondary to palmar and digital arterial occlusion. Ann Plast Surg 1996;37:356-62.

4. Abudakka M, Pillai A, Al-Khaffaf H. Hypothenar Hammer Syndrome: rare or underdiagnosed? Eur J Vasc Endovasc Surg 2006;32:257-60. 